\title{
A Enfermagem do Trabalho em Portugal: Experiência, Motivações, Locais de Trabalho, Formação, Funções, Indicadores produzidos e Condições de Trabalho
}

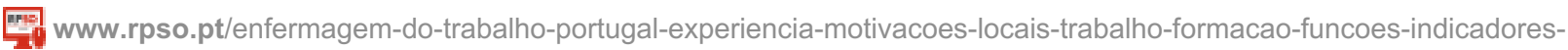
produzidos-condicoes-trabalho/
}

July 20, 2017

THE OCCUPATIONAL HEALTH NURSING IN PORTUGAL: EXPERIENCE, MOTIVATIONS, PLACES OF WORK, TRAINING, FUNCTIONS, INDICATORS PRODUCED AND CONDITIONS OF WORK

TIPO DE ARTIGO: Observacional analítico transversal

AUTORES: Almeida A(1),Santos M(2).

\section{RESUMO}

\section{Introdução}

Na Europa, os enfermeiros são o maior grupo profissional da área da saúde que presta cuidados à população ativa, em contexto laboral. Em Portugal o contributo desses enfermeiros ainda não está devidamente explicado, existindo dúvidas acerca da sua experiência profissional, formação académica e tipo de funções/ papeis que ocupa no contexto da Saúde Ocupacional.

\section{Objetivo}

Pretende-se conhecer a forma como, no momento, se exerce a Enfermagem do Trabalho em Portugal e, desejavelmente, inferir medidas promotoras de mudança para melhor aproveitar o potencial destes profissionais.

\section{Método}

Trata-se de um estudo descritivo, correlacional, de carater transversal, realizado após a aplicação de um inquérito online que contou com a colaboração institucional da Ordem dos Enfermeiros, que disponibilizou o acesso ao questionário através da sua página da internet. A recolha de dados ocorreu entre abril de 2016 e abril de 2017.

\section{Resultados}

Participaram no estudo 87 enfermeiros que, em média, terminaram o curso de enfermagem há 11.86 8.79 anos, embora trabalhem na Saúde Ocupacional acerca de $7.60 \pm 6.54$ anos. As principais motivações para exercerem é a possibilidade de auferirem de um complemento salarial (os mais experientes) ou de um emprego remunerado (os mais jovens), estando em minoria os que pretendem de futuro dedicar-se exclusivamente à Enfermagem do Trabalho. O exercício em empresas de prestação de serviços externos de Saúde Ocupacional (os menos experientes) é centrado, quase exclusivamente, na 
prestação de tarefas de carater instrumental, com pouca autonomia e fracas condições de trabalho (estruturais, de recursos humanos ou remuneratórias). A prestação de serviços internos, em empresas, é vista como compensatória, pois enfoca na prevenção e promoção da saúde, permitindo um acompanhamento de proximidade dos colaboradores, com grande autonomia. Falta contudo, demonstrar maior pro-atividade relativamente aos objetivos da empresa e desenvolver áreas como a conceção de cuidados individualizados, a investigação, a reabilitação e o planeamento em saúde.

Relativamente à formação, a maioria pediu a autorização para exercer, no entanto, apenas uma minoria já adquiriu a formação necessária para a certificação definitiva.

\section{Conclusão}

Atendendo ao potencial salutogénico da Enfermagem do Trabalho e das repercussões que a sua atuação pode ter no mundo laboral, projeta-se que, de futuro, deverá existir um maior investimento na formação, direcionando o foco dos Enfermeiros do Trabalho para a gestão, prevenção e promoção da saúde, apostando num aumento de competências associadas à investigação e ao planeamento em saúde que, comprovadamente, gere ganhos objetivamente mensuráveis.

Palavras-chave: Enfermagem do Trabalho; Enfermeiro do Trabalho; Saúde Ocupacional.

\section{ABSTRACT}

\section{Introduction}

In Europe, nurses are the largest professional group in the health area that provides care to the active population in a work context. In Portugal, the contribution of these nurses is not yet adequately explained, and there are doubts about their professional experience, academic training and the type of roles they occupy in the context of Occupational Health.

\section{Objective}

It is intended to know how Occupational Health Nursing Work in Portugal, to infer measures that promote change in order to better utilize the potential of these professionals.

\section{Methods}

It is a descriptive, cross-sectional study carried out after the application of an online survey that had the institutional collaboration of the Order of Nurses, which provided the questionnaire access through its website. Data collection took place between April 2016 and April 2017.

\section{Results}

The study included 87 nurses who, on average, finished the nursing course $11.86 \pm 8.79$ years, although they work in Occupational Health about $7.60 \pm 6.54$ years. The main motivations for exercising are the possibility of obtaining a salary supplement (the most experienced) or a paid job (the youngest), being in the minority those who intend to dedicate themselves exclusively to the Occupational Health. The exercise in companies 
that provide external occupational health services (the least experienced) is focused almost exclusively on the provision of tasks of an instrumental nature, with little autonomy and weak working conditions (structural, human resources or remuneration). The provision of internal services in companies is seen as compensatory, since it focuses on the prevention and promotion of health, allowing a close monitoring of employees, with great autonomy. However, it is necessary to demonstrate greater pro-activity in relation to the company's objectives and to develop areas such as the design of individualized care, research, rehabilitation and health planning.

Regarding training, most asked for authorization to pursue, however, only a minority has already acquired the training necessary for final certification.

\section{Conclusion}

Given the salutogenic potential of Occupational Health Nursing and the repercussions that its performance may have, it is projected that, in the future, there should be a greater investment in training, directing the focus of Occupational Health Nurses to the management, prevention and Promotion of health, betting on an increase of competences associated with research and health planning that, demonstrably, generate objectively measurable gains

Keywords: Occupational Health Nursing; Occupational Health Nurses; Occupational Health.

\section{INTRODUÇÃO}

Na Europa, os enfermeiros são o maior grupo profissional da área da saúde que presta cuidados à população ativa, em contexto laboral ${ }^{1}$. Em Portugal, apesar de existirem enfermeiros veiculados à Saúde Ocupacional (SO) há já varias décadas ${ }^{2}$, só no início do milénio foi legislada a obrigatoriedade da sua presença no contexto empresarial, através do Decreto-Lei n. ${ }^{\circ} 109 / 2000$ de 30 de Junho, onde é referido que deve exercer a sua atividade com autonomia técnica, desde que demonstre ter experiência adequada ${ }^{3}$. A Lei n. ${ }^{\circ} 102 / 2009$ de 10 de Setembro, veio acrescentar que essa atividade é objeto de legislação especial, inexistente na data da sua publicação ${ }^{4}$. Como consequência, a Direcção-Geral da Saúde emanou a Orientação n. ${ }^{\circ}$ 9/2014 de 03 de junho, tendo em vista a criação de um registo de profissionais de enfermagem detentores de autorização para exercerem na $\mathrm{SO}^{5}$, tendo definido que em Portugal:

"A atividade do Enfermeiro do Trabalho é dirigida à gestão da saúde do trabalhador ou de grupos de trabalhadores. Focaliza-se na promoção e proteção da saúde e bem-estar no local de trabalho, na prevenção de acidentes e doenças relacionadas ou agravadas pelo trabalho, com o propósito de promover ambientes de trabalho saudáveis e seguros" (5 p. 2 ).

Há consenso que, para exercer, o ET (neste artigo a sigla ET significará Enfermeiro do Trabalho ou Enfermagem do Trabalho) necessita de ter comprovado um conjunto de competências, adquiridas após a sua formação inicial ${ }^{1,6,7}$; contudo, em Portugal, apesar da variabilidade curricular da licenciatura em enfermagem, genericamente, não é dado grande 
destaque à $\mathrm{SO}^{8}$ e a formação pós-graduada apenas foi definida pela Direção-Geral da Saúde em Outubro de 20157. A nível europeu a realidade é diferente e a Federation of Occupational Health Nurses within the European Union (FOHNEU) disponibiliza desde 1996 um "Core Curriculum" destinado a orientar essa formação pós graduada 6 , com base no Modelo de Hanasaari ${ }^{6}$ e que visa proporcionar aos enfermeiros conhecimentos e desenvolvimento de competências que incentivem a aprendizagem a um nível superior, "baseado na arte e ciência de enfermagem" (6 $\left.{ }^{\text {p.11}}\right)$; nos Estados Unidos a formação especializada existe já desde 1916, altura em que a Faculdade de Gestão da Universidade de Boston, iniciou um curso intitulado Serviços Laborais para Enfermeiros ${ }^{9}$.

Uma das formas de percecionar o contributo da ET para a sociedade é a produção científica associada à investigação produzida pelos seus profissionais, documentando os ganhos em saúde que resultam da atuação dos enfermeiros; uma revisão bibliográfica sobre a ET no mundo, revelou que ao longo dos últimos anos as tarefas predominantemente curativas deram lugar a outras de prevenção e de gestão ${ }^{1}$, sendo inúmeros os programas que o ET tem capacidade para orientar, centrados na Educação e Promoção para a Saúde, como são exemplos: orientação em Programas de Consumo de Substâncias Psicoativas (tabaco, álcool, marijuana); assessoria a nível de Sustentabilidade Ambiental (em contexto laboral ou até global); promoção da Saúde do viajante; acompanhamento de processos de Lay-offs/ Despedimentos/ Reformas; programas de promoção da amamentação; colaboração com a Higiene e Segurança no trabalho; Tratamento da Obesidade e Ginástica Laboral ${ }^{8}$. O próprio acompanhamento direto do trabalhador (via telefone ou por visita domiciliária) facilita a cura, aumenta a satisfação do funcionário e encurta a ausência ao trabalho e eventuais limitações profissionais posteriores, tenha a situação de base etiologia laboral ou não e referenciando para serviços de saúde mais especializados, quando necessário ${ }^{8}$. Para além disso, dado o teor dos assuntos existentes entre funcionário e entidade empregadora, parte dos quais alvo de sigilo profissional, o ET está em posição privilegiada para, sem nunca quebrar esse ponto, defender os interesses de todas as partes ${ }^{1}$.

A Organização Mundial da Saúde (OMS), legitimando o contributo global da ET para a sociedade, atribui aos enfermeiros o desempenho de diversos papeis na SO, consoante as caraterísticas do contexto onde atuam ${ }^{1}$. Rasteiro ${ }^{2}$, referindo-se ao contexto português, complementa dizendo que as funções que exercem dentro das empresas dependem de uma conjugação de diversos fatores: constituição da equipa de higiene, segurança e saúde; filosofia e política da empresa; preocupações do empregador; preocupações dos empregados e formação dos enfermeiros em saúde ocupacional ${ }^{2}$. No entanto, para que se processe a afirmação do ET em Portugal, ainda há muito para fazer.

A produção científica nacional associada à $\mathrm{ET}^{8,10-12}$ é ainda demasiado escassa para retratar a realidade profissional, justificar os diferentes papéis ou para comprovar os benefícios da sua presença nas empresas, nomeadamente através de resultados mensuráveis na diminuição do absentismo e aumento de produtividade dos colaboradores $^{8,10,12,13}$.

A falta de formação torna-os vulneráveis ao mercado de trabalho e o recrutamento para a SO faz-se muitas vezes para executar pacotes pré-formatados de exames requisitados comercialmente (eletrocardiograma-ECG, acuidade visual e auditiva, glicemia, combur, 
entre outros), por vezes sem relevância ocupacional para o posto em questão, ficando por explorar o real papel que estes poderiam adquirir dentro da Equipa de Saúde Ocupacional. Assim, a maioria das empresas prestadoras de serviços de Saúde Ocupacional e até mesmo os empregadores têm geralmente uma visão extremamente limitada relativa às potencialidades destes profissionais ${ }^{8}$.

Enquanto no seio da profissão de enfermagem se mantém a discussão se a ET deveria tornar-se uma especialidade ou se é uma área da Enfermagem Comunitária com Competências Acrescidas, seria interessante clarificar qual o contributo que estes profissionais têm para dar à sociedade. Assim, com este estudo, pretende-se conhecer a forma como se exerce a ET em Portugal tendo em conta as respostas a um questionário respondido por enfermeiros que exercem funções em SO.

\section{METODOLOGIA}

Trata-se de um estudo descritivo, correlacional, de carater transversal.

A amostragem foi por conveniência e o valor final da amostra representa o número de enfermeiros que trabalham em SO que se prontificaram a responder voluntariamente ao inquérito.

Para a recolha de dados optou-se por um inquérito online; para o efeito obteve-se a colaboração institucional da Ordem dos Enfermeiros que disponibilizou o acesso ao questionário através da sua página da internet. A recolha de dados ocorreu entre abril de 2016 e abril de 2017.

Com o questionário pretendeu-se dar resposta às seguintes questões: 1-Qual a experiência profissional dos enfermeiros que trabalham na SO? 2-Qual a motivação para trabalharem nessa área? 3-Onde trabalham? 4-No futuro, pretendem continuar a trabalhar na SO?; 5-Qual a formação académica? 6- Já solicitaram autorização à DGS para exercerem como ETs? 7-Que funções exercem? 8-Que indicadores de qualidade produzem? 9-Que condições têm para exercer? 10-Quais os fatores positivos e negativos de trabalharem nessa área, na sua perspetiva.

No total, foram operacionalizadas doze variáveis: 1-Experiência profissional como enfermeiro; 2-Experiência profissional na SO; 3-Regime de horário laboral na SO; 4-Tipo de serviços prestados; 5-Formação em SO; 6-Autorização para exercer; 7-Funções exercidas na SO; 8-Produção de Indicadores de Qualidade; 9-Objetivos da entidade empregadora; 10-Autonomia para exercer; 11-Pontos positivos de exercer ET (resposta aberta); 12-Pontos negativos de exercer ET (resposta aberta).

Para as variáveis 11 e 12, realizou-se análise qualitativa das respostas, até à obtenção de categorias, que posteriormente foram acrescentadas à base de dados inicial, para realizar a análise quantitativa.

A normalidade da distribuição de cada variável foi avaliada por meio do teste de Kolmogorov-Smirnov. No tratamento estatístico foram utilizadas medidas de tendência central para descrever os achados. Para a análise inferencial, usou-se o teste do Qui 
quadrado, para relações entre variáveis categóricas, bem como os testes T e Anova para amostras independentes, para relações com variáveis contínuas. A relação entre as variáveis será dada pelo valor de $p$. Para valores de $p<0.05$ rejeita-se a hipótese nula ou seja a probabilidade das diferenças registadas na amostra serem devidas ao acaso é muito pequena. Caso o p>0,05, considera-se que não existe evidência suficiente para rejeitar a hipótese nula. Os dados foram processados com a ajuda do SPSS $_{24}$.

\section{RESULTADOS}

Responderam ao inquérito 87 enfermeiros que exercem a sua atividade profissional na So.

\section{1-Qual a experiência profissional dos enfermeiros que trabalham na SO?}

Os enfermeiros da amostra, em média, terminaram o curso de enfermagem há $11.86 \pm 8.79$ anos; $41.9 \%$ trabalha há mais de uma década, 32.6\% entre cinco e dez anos e apenas $25.6 \%$ exerce enfermagem há menos de cinco anos (Gráfico 1).

Analisando a experiência de trabalho em SO, a média desce para os $7.60 \pm 6.54$ anos; a maioria (51.2\%) trabalha há menos de cinco anos, $23.8 \%$ entre seis e dez e apenas $25 \%$ o faz há mais de dez anos (Gráfico 1).

\section{2-Qual a motivação para trabalhar na SO?}

O exercício de funções na SO é visto como complemento salarial de um primeiro emprego para $39.8 \%$ e apenas como primeira opção para $25.3 \%$; os $34.9 \%$ restantes trabalham na SO porque não conseguiram arranjar emprego noutra área da sua preferência. Em média, quem veio por opção ou para obter um suplemento financeiro, trabalha há mais anos e tem mais experiência em SO do que aqueles que o fazem somente por necessidade (Gráfico 2), sendo a diferença estatisticamente significativa ( $F=14.147 ; p<0.001$ e $F=12.486$; $p<0.001$ ). Analisando o tipo de serviços prestados (internos ou externos), observam-se diferenças estatisticamente significativas entre os três grupos $\left(X^{2}=8.099 ; p=0.17\right)$; os que escolheram a SO trabalham maioritariamente em empresas, integrados na equipa de SO; os que o fazem como segundo emprego distribuem-se uniformemente; quem trabalha por obrigação, presta fundamentalmente serviços externos de SO. Apesar das diferenças no terceiro grupo, $85.7 \%$ refere gostar do que faz; os restantes trabalham para se sustentar economicamente.

Apenas $41.4 \%$ ocupa o seu tempo integral como enfermeiro na área da SO; a maioria exerce em tempo parcial, dos quais $24.1 \%$ faz mais de dez horas semanais, $23 \%$ menos de dez, enquanto $11.5 \%$ apenas o faz esporadicamente (Gráfico 3). O teste $\mathrm{T}$ revela que os que trabalham mais horas por semana na SO exercem enfermagem, em média, há menos tempo (10.34 \pm 8.2$)$, do que aqueles que o fazem menos de dez horas ou esporadicamente (14.70 \pm 9.2$)$; a diferença é estatisticamente relevante $(t=-2.238$; $p=0.028)$.

\section{3- Onde exercem profissionalmente os Enfermeiros do Trabalho?}


A amostra divide-se entre o exercício profissional em empresas externas de prestação de serviços de SO (54.7\%) e serviços internos, integrados numa equipa de SO (45.3\%) (Gráfico 4). O teste T Student comprova que, em média, os enfermeiros que fazem serviço

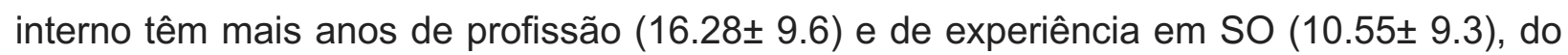
que os que trabalham em empresas externas de SO - (8.03 \pm 5.9$)$ e $(5.10 \pm 4.5)$. As diferenças são estatisticamente significativas $(t=-4.650 ; p<0.001)$ e $(F=-3.945 ; p<0.001)$ respetivamente.

\section{4-Onde gostariam de trabalhar futuramente?}

No futuro apenas $38.8 \%$ pretende dedicar-se integralmente à SO, 49.4\% quer manter essa atividade em regime parcial e $11.8 \%$ afirma não desejar continuar a trabalhar na área (Gráfico 5); é de realçar que os que pretendem abandonar exercem, sem exceção, em empresas de prestação de serviços externos de $S O\left(X^{2}=9.762 ; p=0.008\right)$. Associando a variável à experiência acumulada na $S O$, o teste Anova permite concluir que existem diferenças estatisticamente significativas entre grupos $(F=3.575 ; p=0.033)$. O teste de Tukey revela que os que pretendem continuar a trabalhar integralmente na ET, em média, trabalham há mais anos na SO $(9.22 \pm 6.5$ anos; $p=0.025)$, seguindo-se os que pretendem permanecer em regime parcial $(7.50 \pm 6.7$ anos; $p=0.124)$, face aos que não tencionam investir na área $(2.83 \pm 2.3$ anos). Relativamente à experiência profissional como enfermeiros, apesar da diferença entre grupos não ser estatisticamente significativa $(F=2.667 ; p=0.076)$, também aqui se verifica que os mais experientes, em média, são os que demonstram querer continuar a exercer integralmente na SO (13.1 \pm 9.3$)$, enquanto os menos experientes aguardam por uma oportunidade para abandonar $(6.1 \pm 4.3)$.

\section{5-Qual a formação académica dos enfermeiros que exercem na SO?}

Analisando o perfil de competências certificadas, constata-se que apenas $34.5 \%$ possui a formação obrigatória, definida pela DGS, para a certificação definitiva como Enfermeiro do Trabalho (Gráfico 6). É de realçar, o contributo das recentes Pós-Graduações em Enfermagem do Trabalho, responsável pela formação obrigatória de $46.7 \%$ da amostra.

O teste $T$ revela que, em média, quem já tem competências certificadas é mais experiente

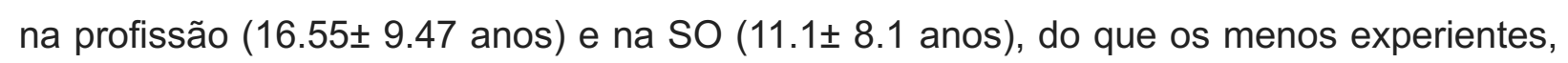
$(9.4 \pm 7.4)$ e $(5.7 \pm 4.6)$ respetivamente. As diferenças são ambas estatisticamente significativas $-(\mathrm{t}=3.792 ; p<0.001)$ e $(\mathrm{t}=3.260 ; p=0.002)$.

Apesar do teste do Qui-quadrado não revelar diferenças significativas $\left(X^{2}=2.381 ; p=0.173\right)$, é possível verificar na Tabela 1 que a existência de formação obrigatória para exercer é mais comum nos enfermeiros que fazem serviço interno do que nos restantes.

\section{6-Já solicitaram autorização à DGS para exercerem como ET?}

Relativamente à formalização do pedido para exercer como enfermeiro do trabalho, reconhecido pela DGS, apenas $29.1 \%$ referiu não possuir a autorização, não estando esta decisão dependente da experiência profissional ( $t=-0.203 ; p=0.840)$, da experiência em SO $(t=0.921 ; p=0.017)$ ou do tipo de serviço prestado $\left(X^{2}=0.629 ; p=0.480\right)$. 
Dos $70.9 \%$ registados, $32.8 \%$ tem a formação necessária para a certificação definitiva, $52.5 \%$ não tem ainda formação mas pretende obtê-la, enquanto $14.8 \%$ não tem, nem pretende adquirir mais formação (Gráfico 7).

O teste Anova permite concluir que existem diferenças estatisticamente significativas entre grupos relativamente ao número de anos de experiência profissional como enfermeiro $(F=4.270 ; p=0.019)$ ou na SO $(F=7.813 ; p=0.001)$. Analisando as diferenças, constata-se que quem já fez a formação adequada para a certificação como $E T$, tem mais anos de experiência profissional (16.47 \pm 9.1 anos) e de SO (12.3 \pm 7.4 anos), do que aqueles que ainda pretendem fazer ( $9.85 \pm 8.9$ e $5.79 \pm 5.1$ anos) ou dos que não têm intenções de a

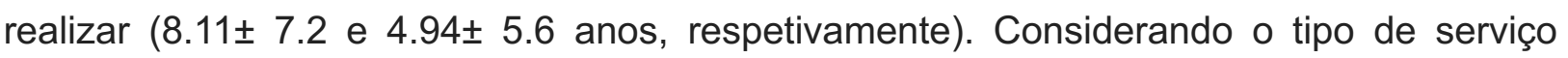
realizado, também aqui se verificam diferenças significativas entre grupos $\left(X^{2}=8.093\right.$; $p=0.020$ ), ou seja, os que não pretendem realizar a formação obrigatória trabalham, quase exclusivamente, para empresas de serviços externos, enquanto os que já a têm prestam, maioritariamente, serviço interno numa empresa (Tabela 2).

\section{7-Que funções atribuem as empresas aos ET?}

Explorando as diferentes funções executadas pelos enfermeiros da amostra (Tabela 3), pretende-se averiguar se há diferenças significativas na sua atuação em contexto laboral, tendo em conta a potencial influência das variáveis: formação, número de anos de profissão e experiência profissional como enfermeiro, na área da SO.

\section{-Executar exames auxiliares de diagnóstico (87.1\%)}

A execução de exames médicos auxiliares de diagnóstico é a tarefa que reúne maior consenso, sendo realizada por $87.1 \%$ dos profissionais; estas funções derivam das responsabilidades contratuais negociadas entre as empresas prestadores de serviços de SO e as empresas cliente (21.8\%), da decisão exclusiva da equipa de SO $(41.3 \%)$ ou de ambas (28.7\%).

Relativamente à influência da formação em SO para a realização de exames auxiliares de diagnóstico, o teste de Qui-quadrado não comprovou a existência de associações estatísticas relevantes; observa-se, no entanto, que os profissionais que têm formação, normalmente envolvem-se mais na realização de exames prescritos pela equipa de $\mathrm{SO}$, do que os restantes ( $V$ de Cramer=0.209; $p=0.084$ ).

O teste $T$ revela que, em média, os profissionais com menos anos de profissão $(8.13 \pm 5.2)$ e de experiência profissional em SO $(5.63 \pm 4.4)$, dedicam-se mais a realizar exames auxiliares de diagnóstico determinados por contrato comercial, do que os enfermeiros com mais anos de profissão $(15.59 \pm 10)$ ou mais experientes nas funções de ET $(9.48 \pm 7.6)$, sendo as diferenças estatisticamente significativas $(t=-4.320 ; p<0.001)$ e $(t=-2.840$; $\mathrm{p}=0.006) ;$ a realização destes exames está também associada aos enfermeiros que trabalham para empresas de SO que prestam serviços externos $\left(X^{2}=20.691 ; p<0.001\right)$.

Simultaneamente, também se observa que, em média, os profissionais com mais anos de

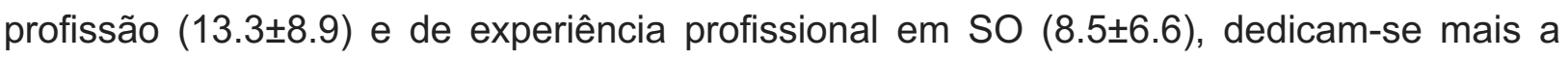
realizar exames auxiliares de diagnóstico determinados pela equipa de $\mathrm{SO}$, do que os

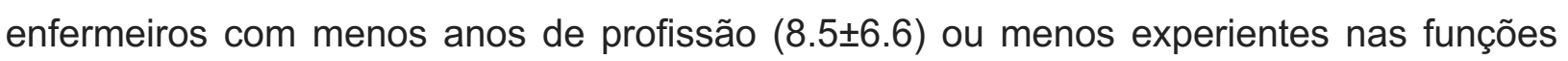


(5.3 \pm 5.8$)$, sendo as diferenças estatisticamente significativas $(t=2.837 ; p=0.006)$ e ( $t=2.041 ; p=0.044)$; o resultado do teste do Qui-quadrado associa a este tipo de tarefas os profissionais que prestam serviços internos em empresas $\left(X^{2}=6.482 ; p=0.001\right)$.

\section{-Quantificação de parâmetros biomédicos (66.7\%)}

Com $66.7 \%$ destaca-se a quantificação de parâmetros biomédicos, nos trabalhadores, como a avaliação da tensão arterial, registo de glicemia ou colesterol. O teste de Quiquadrado revela que há diferenças estatísticas significativas relativas à execução deste tipo de tarefas $(p=0.008)$, estando essencialmente associadas, aos enfermeiros que ainda não possuem formação específica em SO (V de Cramer=0.038; $p=0.007$ ); associam-se ainda, em média, aos profissionais com menos experiência na área $(t=-2.422 ; p=0.020) e$ apesar de não ser estatisticamente significativo, é uma tarefa maioritariamente realizada por enfermeiros que exercem em empresas de prestação de serviços de $S O\left(X^{2}=3.955\right.$; $p=0.065)$.

\section{-Execução de cuidados curativos (58.6\%)}

Ainda acima dos $50 \%$ surge a realização de cuidados curativos em resposta a lesões contraídas pelos trabalhadores, como é o caso do tratamento de feridas e da administração de medicamentos; apesar do teste do Qui-quadrado não revelar diferenças estatisticamente significativas, os números revelam que a expectativa das empresas face à execução deste tipo de funções aumenta, relativamente aos profissionais de enfermagem sem formação específica, com pouca experiência profissional e/ou de SO e que fornecem serviços através de empresas de SO.

\section{-Realizar ações de educação para a saúde pré determinadas pela Equipa de SO (ESO)}

O envolvimento em ações de educação para a saúde determinadas pela ESO (54\%), contribuindo dessa forma, para aumentar o conhecimento dos trabalhadores e a participação no diagnóstico de necessidades de formação $(52.9 \%)$ relacionadas com a saúde dos trabalhadores da empresa, não regista assimetrias na distribuição estatística relativa à formação e experiência profissional da amostra. Contudo, apesar de não serem estatisticamente relevantes, observa-se que em ambas as tarefas há uma maior participação dos enfermeiros que prestam serviços internos nas empresas.

\section{-Apoio logístico a projetos idealizados pela entidade patronal (52.9\%)}

Em oposição, o apoio logístico a projetos idealizados pela entidade patronal, colaborando na sua operacionalização, apesar da diferença não ser estatisticamente relevante, parece mais associado aos enfermeiros que trabalham para empresas de SO.

\section{-Serviços de socorrismo e emergência médica (43.7\%)}

A prestação de serviços relacionados com socorrismo ou atuação em casos de emergência médica foi referenciada por $43.7 \%$ da amostra. A aplicação do teste do Quiquadrado revela diferenças estatisticamente significativas mediante a formação dos profissionais de enfermagem $(p=0.024)$. Assim, a prestação destes serviços é mais requisitada aos profissionais sem formação específica na área de SO (V de Cramer=0.249; 
$\mathrm{p}=0.023)$; apesar do teste $\mathrm{T}$ não revelar associações estatísticas significativas com a experiência profissional de enfermagem ( $t=-1.606 ; p=0.112)$ ou na SO $(t=-1.961$; $\mathrm{p}=0.053)$, em média, os menos experientes dedicam-se mais a estas funções $(10.1 \pm 7.9 \mathrm{e}$ $6.1 \pm 4.9$ anos) do que os mais experientes (13.2 \pm 9.2 e $8.7 \pm 7.4$ anos). Relativamente ao tipo de serviços prestados, não se registam diferenças relevantes.

\section{-Gestão administrativa dos serviços de SO (40.2\%)}

A gestão administrativa dos serviços de $S O$, que engloba um conjunto de funções destinadas à manutenção funcional da equipa de SO, é desempenhada por cerca de $40.2 \%$ da amostra, não se verificando diferenças estatisticamente significativas com o nível de competências, experiência profissional ou tipo de serviços prestados pelos enfermeiros.

\section{-Apoio administrativo à ESO (37.9\%)}

Acima dos $30 \%$ surge o apoio administrativo à ESO, que passa essencialmente pela coadjuvação do Médico do Trabalho. Apesar de não existir associação estatística relevante com o nível de formação $\left(X^{2}=1.223\right.$; $\left.p=0.354\right)$, o teste $T$ permite comprovar, com significância estatística ( $t=-2.599 ; p=0.011$ e $t=-2.325 ; p=0.023)$ que, em média, quem desempenha este tipo de funções trabalha há menos anos como enfermeiro $(8.9 \pm 6.8)$ e

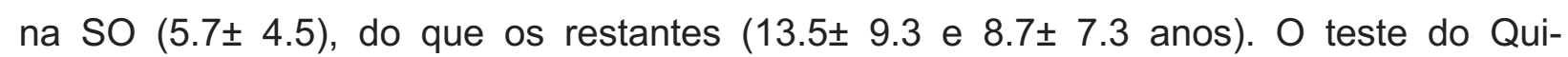
quadrado também associa maioritariamente a esta tarefa aos enfermeiros que prestam serviços através de empresas de SO $\left(X^{2}=4.891 ; p=0.044\right)$.

\section{-Gestão da saúde ocupacional/ pessoal do trabalhador (37.9\%)}

A gestão da saúde ocupacional do trabalhador, incidindo sobre as particularidades de saúde relacionadas com o trabalho de cada colaborador da empresa e o empoderamento face às necessidades de gestão da saúde individual identificadas em cada trabalhador (32.2\%), não têm associação estatística relevante com a existência de formação específica em SO, com a experiência profissional ou com o tipo de serviços prestados.

\section{- Apoio ao plano de formação da empresa (33.3\%)}

A participação nas ações de educação para a saúde definidas pela empresa, consagradas no programa interno de formação profissional, também não tem associação estatística relevante com a existência de formação específica em SO, com a experiência profissional ou com o tipo de serviços prestados.

\section{-Desenvolvimento de projetos de melhoria das condições de saúde (31\%)}

O desenvolvimento de projetos de intervenção centrados na melhoria das condições saúde/ laborais, congruente com o assumir da responsabilidade por contribuir de forma ativa/ produtiva para a empresa, não têm associação estatística relevante com a existência de formação específica em SO; analisando a experiência profissional, constata-se que, em média, os trabalhadores que assumem essa responsabilidade trabalham como enfermeiros $(10.4 \pm 8.4)$ e na SO $(6.7 \pm 6.7)$ há menos anos do que aqueles que não propõem mudanças (12.5 8.9 e $8.0 \pm 6.4$ anos), embora as diferenças não sejam estatisticamente significativas $(t=-0.988 ; p=0.326$ e $t=-0.826 ; p=0.411)$. Não se observam diferenças relevantes relativas ao tipo de serviços prestados. 


\section{-Executar estudos epidemiológicos (25.3\%)}

Cerca de um quarto da amostra refere ainda que executa estudos epidemiológicos na empresa, visando a saúde dos trabalhadores; apesar do teste Qui-quadrado não identificar diferenças relevantes $\left(X^{2}=3.138 ; p=0.118\right)$ entre os grupos, é possível verificar que quem não tem formação específica em SO, se envolve menos nestas tarefas. Relativamente à experiência profissional, o teste $\mathrm{T}$ não comprova a existência de associação estatística significativa, contudo, é possível constatar que, em média, quem realiza estudos epidemiológicos é normalmente mais experiente $(14.5 \pm 10.5)$ do que quem não os faz (10.9 \pm 7.9), embora tal resultado não se verifique relativamente à experiência de trabalho em SO (7.0 7.1 contra $7.7 \pm 6.3$ anos). Relativamente ao tipo de serviços prestados, constata-se que os enfermeiros que exercem internamente nas empresas realizam com mais probabilidade este tipo de estudos $\left(X^{2}=6.219 ; p=0.015\right)$.

\section{-Cuidados de reabilitação dos trabalhadores (18.4\%)}

Abaixo dos $20 \%$ surgem os cuidados de reabilitação em contexto laboral, normalmente muito associados a situações de lesões musculosqueléticas. O teste Exato de Fisher revela que não há evidência de que a formação tenha qualquer influência na concretização deste tipo de cuidados em contexto laboral $(p=0.552)$. $O$ teste $T$ também não comprova a associação com o número de anos de trabalho $(p=0.132)$ ou com a maior experiência profissional em SO ( $p=0.112)$, no entanto, é de realçar que, em média, os que se envolvem

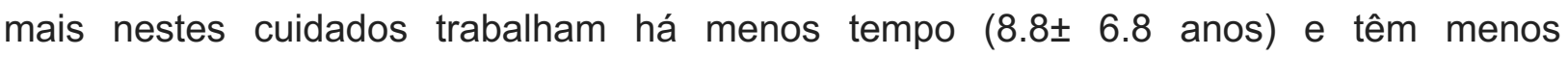

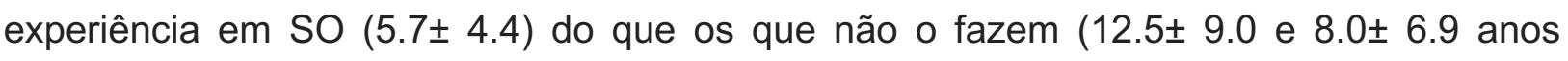
respetivamente). Apesar do teste do Qui-quadrado não comprovar diferenças significativas entre grupos, este tipo de tarefas parece mais associada a enfermeiros que exercem internamente nas empresas.

\section{-Gestão financeira dos serviços}

A gestão financeira do serviço de SO é apenas realizada por $10.3 \%$ da amostra e não há associação estatística relevante com a existência de formação certificada $(p=0.489)$, anos de experiência profissional $(p=0.335)$, de trabalho em SO $(p=0.629)$ ou do tipo de serviços prestados $(p=0.726)$.

\section{-Familiares e apoio domiciliário}

Todas as funções relacionadas exclusivamente com a saúde de familiares de trabalhadores ou com a possibilidade de o ET efetuar visitações fora do ambiente empresarial tiveram uma expressão residual, não se configurando, por isso, como importantes para caraterizar as fronteiras de atuação da ET, desta amostra.

\section{8-Que indicadores de qualidade produzem os ET?}

Os enfermeiros que responderam ao inquérito caraterizaram a sua participação relativamente à produção de indicadores de estrutura, processo e resultado, importantes para a gestão da qualidade dos Serviços de Saúde Ocupacional e das empresas onde trabalham. 
A grande maioria (77\%) admitiu que o seu trabalho gerava indicadores de processo úteis para a empresa. Analisando as diversas variáveis que caraterizam a amostra, o teste do Qui-quadrado revela que existem diferenças estatisticamente significativas entre a produção de indicadores de processo e o número de horas semanais de trabalho na SO $\left(X^{2}=7.485\right.$; $\left.p=0.008\right)$, ou seja, quem tem horário integral ou parcial superior a 10 horas semanais, tem maior probabilidade de os produzir do que quem trabalha menos ou esporadicamente. $O$ teste $t$, apesar de também não registar diferenças significativas ( $t=$ 0.685; $p=0.495$ ), demonstra que quem produz estes indicadores, em média, trabalha há menos tempo $(11.5 \pm 8.0)$ do que quem não os produz (13.05 \pm 10.9$)$. Não se observaram quaisquer outras relações estatísticas relevantes.

\section{-Indicadores de estrutura}

Apenas $48.3 \%$ da amostra refere produzir indicadores de estrutura para gerir os recursos associados ao seu trabalho. Apesar de não ser estatisticamente significativo $\left(X^{2}=1.638\right.$; $p=0.279$ ), os enfermeiros que exercem SO nas empresas têm maior probabilidade de produzir este tipo de indicadores. Não se observaram quaisquer outras relações estatísticas relevantes.

\section{-Indicadores de resultado}

Por último, somente $26.4 \%$ da amostra se preocupa com a produção de indicadores de resultado, garantindo dessa forma uma correta avaliação da qualidade do cuidado prestado e permitindo aferir o contributo do serviço de enfermagem para a produção da empresa. Apesar de não ser estatisticamente significativo $\left(X^{2}=0.590 ; p=0.472\right)$, os enfermeiros que exercem SO nas empresas têm maior probabilidade de produzir este tipo de indicadores. Não se observaram quaisquer outras relações estatísticas relevantes.

\section{9-Que condições têm os ET para exercer?}

A amostra, na sua maioria (67.8\%), considera que as entidades empregadoras têm interesse genuíno em proporcionar o melhor serviço possível de SO.

Analisando as diferenças relativas ao tipo de serviços prestados, apesar de não serem estatisticamente significativas $\left(X^{2}=2.293 ; p=0.164\right)$, há maior probabilidade das empresas prestadoras de serviços de SO proporcionarem piores condições aos seus enfermeiros do que as restantes. A aplicação do teste t permite concluir que, em média, os enfermeiros que trabalham em empresas com interesse genuíno em fornecer bons serviços de SO são mais velhos $(12.37 \pm 9.4)$ do que os restantes (10.82 \pm 7.4$)$, embora a diferença não seja estatisticamente relevante $(t=4.482 ; p=0.410)$. Não se observaram relações relevantes com a aquisição de competências.

Questionados acerca da existência de autonomia para gerir tarefas e propor novas atividades, apesar de não se identificarem diferenças estatisticamente significativas $\left(X^{2}=2.293\right.$; $\left.p=0.164\right)$, é possível observar que com maior probabilidade, as empresas prestadoras de serviços externos de SO não proporcionam aos seus enfermeiros tal abertura. $O$ teste $t$, apesar de também não ser significativo $(t=6.007 ; p=0.115)$, permite 
concluir que, em média, quem tem mais autonomia, trabalha há mais anos na enfermagem

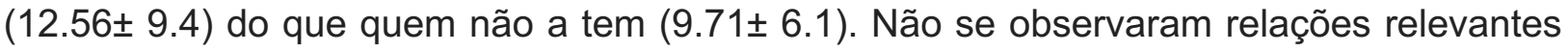
face à aquisição de competências.

\section{0-Vantagens e desvantagens de trabalhar na SO?}

Analisando as respostas dos enfermeiros da amostra constata-se que existiu maior consonância ao elencar os fatores positivos (Gráfico 8), sendo maior a divergência relativamente aos negativos (Gráfico 9 ).

\section{-Aspetos positivos}

A possibilidade de trabalhar diariamente na prevenção de acidentes e de doenças profissionais (24.41\%), bem como na promoção da saúde dos trabalhadores $(24.41 \%)$, foram considerados os aspetos mais positivos de trabalhar na SO.

O acompanhamento de proximidade dos colaboradores, referido por $17.24 \%$, é igualmente observado como facilitador para o exercício de funções, dada a possibilidade de poder contactar diariamente com os mesmos e assumir um planeamento individual com vista à sua melhoria.

O exercício autónomo da profissão é para $13.95 \%$ a principal virtude da ET, pois diariamente são convidados a exercer a tomada de decisão face aos problemas de saúde dos colaboradores e/ ou necessidades da empresa, beneficiando do reconhecimento pelo trabalho efetuado.

A relação terapêutica estabelecida com os clientes do serviço de saúde ocupacional é encarada por $10.46 \%$ como estruturante para a satisfação profissional, algo que não conseguem vislumbrar noutros contextos, dada a confiança que alguns trabalhadores depositam no ET.

Com menor expressividade surgem ainda a possibilidade de proporcionar melhores condições de trabalho que influenciam a vida de algumas pessoas (5.81\%), a oportunidade de trabalhar numa área pouco desenvolvida e que oferece inúmeras oportunidades profissionais (4.65\%), o dinamismo de trabalhar numa empresa onde tudo pode acontecer $(3.48 \%)$ ou de trabalhar verdadeiramente em equipa com os restantes elementos da ESO $(3.48 \%)$.

Isoladamente surgiram ainda outros fatores considerados como positivos como: sentir-se valorizado profissionalmente pela entidade patronal e colaboradores; poder concretizar projetos de intervenção que contribuem para a produção da empresa; agir como interlocutor face aos problemas laborais identificados; produzir objetivamente ganhos em saúde; não estar no desemprego e não ter de trabalhar aos fins de semana.

\section{-Aspetos negativos}

O fator mais vezes destacado como negativo pelos enfermeiros da amostra $(20.93 \%)$ foi a falta de reconhecimento que existe relativamente ao papel do ET, quer pela entidade patronal, colaboradores ou até mesmo, pela Enfermagem em geral.

Próximos dos $10 \%$ surgem a falta de colaboração das entidades patronais que apenas têm 
a SO por obrigação legal e exigem que se faça o mínimo possível, apenas para dar resposta a essa imposição (9.30\%); as condições de trabalho nas empresas cliente, descritas como deficitárias $(8.13 \%)$, tendo em conta que por vezes é exigido que se façam muitos exames auxiliares de diagnóstico, num espaço temporal demasiado restrito e com condições ambientais adversas; a remuneração salarial escassa, em virtude do volume de trabalho exigido e da atitude das empresas cliente e dos seus colaboradores face à presença da SO (8.13\%); e a falta de interesse manifestado pelos colegas de trabalho relativamente à SO $(8.13 \%)$, optando pela realização de tarefas rotinizadas para ocupar o tempo de trabalho (como a realização de exames auxiliares de diagnóstico) ao invés de serem mais pró-ativos.

Menos expressivos surgem os entraves da entidade patronal à atuação da ESO (6.97\%), instigando conflitos relacionados com a manutenção do sigilo profissional e/ ou prestação de cuidados de saúde; a falta de legislação que regule o exercício da profissão na SO e atribua à ET o estatuto que ela necessita para se poder afirmar (5.81\%); a existência de contratos comerciais, sujeitos a pressões externas, com objetivos puramente económicofinanceiros e que limitam a atuação da ESO (5.81\%); a falta de recursos humanos e materiais que obriga o ET a realizar diversas tarefas que não lhe competem e a trabalhar em locais sem condições mínimas para exercer (5.81\%); a reduzida carga horária atribuída por lei ao ET que dificulta a sua atuação nas empresas, não indo além das tarefas exigidas por lei (5.81\%); a ausência de formação dos profissionais para exercer na área, pois limita o desenvolvimento e a afirmação do Enfermeiro do Trabalho em Portugal (4.65\%); e a falta de autonomia para exercer, referida por $3.48 \%$ da amostra, que define a prática de ET como a execução em série de tarefas pré-definidas.

Por último, surgem diversas alusões dispersas a fatores considerados como negativos, que têm pouca expressividade estatística, nomeadamente: a não adesão dos trabalhadores às recomendações da ESO; a necessidade de ter de realizar apoio administrativo relativamente aos outros elementos da ESO; a falta de literacia social relativamente à SO; a inexistência de uma especialidade em ET; a resistência à mudança existente nas empresas; a elevada exigência física que algumas tarefas acarretam; a falta de supervisão externa por parte das autoridades; a ausência de consultas de enfermagem; a inexistência de sistemas de informação que permitam concretizar o processo de enfermagem; e o enfoque ser, muitas das vezes, puramente centrado no ganho económico.

\section{DISCUSSÃO DOS RESULTADOS}

A amostra é maioritariamente constituída por enfermeiros com vários anos de experiência profissional, embora mais de metade trabalhe na SO há menos de cinco anos. A opção pela área não parece advir do curso de licenciatura, sendo habitual a transição dar-se após alguns anos de experiência clínica. A falta de formação específica ao nível do primeiro ciclo (licenciatura) e a responsabilidade acrescida de assumir sozinho os trabalhadores de uma empresa, numa fase tão precoce da profissão, poderão estar na base dessa decisão e justificam que, para Portugal, se exija formação, no mínimo, pós graduada, capaz de sustentar a tomada de decisão. 
O exercício da profissão nesta área continua a ser visto como transitório e encarado como um complemento salarial para quem já trabalha ou para quem ainda não arranjou emprego noutra área. Nesse sentido é o fator experiência profissional que separa estes dois grupos, estando os horários complementares (com poucas horas semanais) associados a enfermeiros mais experientes, que trabalham em regime de acumulação, enquanto os horários integrais são desempenhados pelos profissionais menos experientes. Estes resultados talvez expliquem o pouco investimento em formação específica em SO demonstrado pela amostra, pois apesar de $48.8 \%$ trabalhar em SO há mais de cinco anos, apenas $34 \%$ tem competências certificadas para o fazer.

Os resultados são claros e permitem dividir os enfermeiros da amostra por duas realidades distintas: trabalhar em empresas que prestam serviços externos de $\mathrm{SO}$ ou exercer inseridos nas ESO das próprias entidades empregadoras.

Nos últimos anos, o incremento de leis que visam proteger a saúde dos trabalhadores foi acompanhado por um aumento do número de empresas que se dedicam a fornecer serviços externos de SO; simultaneamente, a falta de emprego que afeta os recémlicenciados em enfermagem no mercado nacional e a ausência de regulação para o exercício de funções na SO, forneceu a estas empresas profissionais da saúde aptos para trabalhar em diversos ambientes e com grande capacidade de adaptação, a preços reduzidos. Não é, por isso, aleatório, que esses enfermeiros tenham maior probabilidade de trabalhar há menos tempo na enfermagem e na SO (em média, têm cerca de metade da experiência profissional) e possuir menos competências certificadas para exercer na área, quando comparados com os enfermeiros que fazem serviço interno. Paradoxalmente, apesar de ser o grupo que se demonstra mais insatisfeito com o trabalho que realiza, é o que mais horas dedica à SO (normalmente em regime integral), mesmo exercendo em empresas que não apostam na qualidade dos serviços e que não proporcionam condições para exercer com autonomia técnica, tal como está mencionado na lei; estes fatores talvez expliquem o facto de uma percentagem considerável de profissionais da amostra (todos pertencentes a este grupo) não pretender continuar a investir na área.

Analisando as tarefas a que se dedicam e que realizam com maior probabilidade do que os enfermeiros que prestam serviços internos, sobressaem as competências técnicas que resultam da prescrição de outros membros da ESO ou das obrigações relativas ao contrato comercial estabelecido entre a sua entidade patronal e as empresas, nomeadamente a realização de exames auxiliares de diagnóstico, administração de fármacos e tratamento de feridas, quantificação de parâmetros biomédicos, bem como apoio administrativo à ESO e a projetos desenvolvidos pela entidade patronal.

Estes resultados justificam que a produção de indicadores de processo esteja estatisticamente associada aos profissionais menos experientes e a tempo integral, pois normalmente dedicam-se a tarefas de carater técnico e são contratados para assegurarem essas funções, sendo o seu trabalho avaliado com base em metas pré-estabelecidas. Daqui resulta a produção de indicadores de produtividade descontextualizados de qualquer indicador de resultado (por exemplo, ganhos em saúde do trabalhador, diminuição do absentismo, aumento da produtividade laboral), o que inviabiliza o reconhecimento de competências socialmente desejadas e financeiramente valorizáveis, 
sendo a ET observada pelas empresas como uma imposição legal que consome recursos, em vez de ser percecionada como um ativo económico.

Por último, quem trabalha em empresas prestadoras de serviços de SO caracteriza, com maior frequência, negativamente, o seu ambiente laboral, donde se destacam fatores como: as condições deficitárias de trabalho nas empresas cliente; a remuneração salarial escassa; a pressão resultante da existência de contratos comerciais; a falta de recursos humanos e materiais; a falta de autonomia para exercer; a obrigatoriedade de realizar apoio administrativo; a elevada exigência física de algumas tarefas; o enfoque centrado puramente no ganho económico.

Em comparação, os enfermeiros que prestam serviços internos de SO têm maior probabilidade de serem profissionalmente mais experientes, trabalharem há mais tempo na SO, terem mais competências específicas certificadas, serem mais autónomos e exercerem em empresas que apostam na qualidade dos serviços prestados pela ESO. Em termos de funções, têm maior probabilidade de executar exames prescritos pela ESO, colaborar na identificação de necessidades de formação e como formadores, realizando ações de educação para a saúde com base nas necessidades identificadas pela ESO ou pela empresa, realizar estudos epidemiológicos e participar na reabilitação dos colaboradores.

$\mathrm{Na}$ realidade, este grupo é o que perceciona uma maior percentagem de benefícios associados ao facto de trabalharem na SO, com destaque para: a possibilidade de trabalhar diariamente na prevenção e promoção da saúde; O acompanhamento de proximidade e a relação terapêutica estabelecida com os colaboradores; a possibilidade de proporcionar melhores condições de trabalho; as oportunidades de trabalhar numa área pouco desenvolvida; o dinamismo de trabalhar numa empresa e de trabalhar em equipa com os restantes elementos da ESO.

O estudo revela ainda que, na generalidade, as empresas têm interesse genuíno em proporcionar o melhor serviço possível de SO, no entanto, por parte dos enfermeiros esperam ainda, quase exclusivamente, a concretização de tarefas complementares a outros técnicos e que exigem maioritariamente, o desempenho de competências meramente instrumentais (por exemplo, a realização de exames e a quantificação de parâmetros biomédicos), tal como referem alguns autores ${ }^{8}$.

A análise revela ainda que o potencial terapêutico dos enfermeiros, resultante da aplicação do processo de enfermagem e baseado em pilares como o acompanhamento de proximidade dos colaboradores e, por vezes, suas famílias, bem como o estabelecimento de relações terapêuticas capazes de gerar modificações comportamentais com vista à melhoria das condições de saúde e qualidade de vida, está ainda muito pouco desenvolvido para ser associado aos indicadores de produtividade laboral das empresas.

O desempenho de papéis ao nível da investigação e gestão, centrados no desenvolvimento produtivo das empresas, quer através da realização de estudos epidemiológicos, construção de projetos de intervenção economicamente sustentáveis ou participação ativa na reabilitação dos colaboradores, quase não têm expressão nesta amostra, justificando a fraca produção de indicadores de resultado e considerando que a 
enfermagem para se poder afirmar no mundo laboral necessita de assumir um papel mais pró-ativo nas empresas, demonstrando que o seu trabalho pode contribuir para a melhoria das condições de saúde dos trabalhadores, diminuição do absentismo ou aumento da produtividade $1,8,10,13$.

\section{CONCLUSÕES}

A ET está a atravessar um processo de mudança em Portugal, beneficiando de um reconhecimento da sua importância por parte da Direção-Geral da Saúde.

A aposta na formação dos ET é um primeiro passo e o início das pós-graduações nessa área é visto como uma resposta, em tempo útil, às necessidades do setor.

Este estudo permitiu identificar duas realidades distintas, o exercício de enfermagem em empresas de prestação de serviços externos de saúde ocupacional, aparentemente carenciados de condições estruturais e processuais para que se atinja o potencial terapêutico da ET, tal como está preconizado pela OMS e a prestação de serviços internos, integrados nas empresas, onde é necessário aumentar a capacidade empreendedora dos ET, transformando-os em elementos pró-ativos, capazes de investigar as fragilidades associadas à saúde e potenciar a produtividade através de projetos de intervenção economicamente viáveis, valorizados pelos colaboradores e entidade patronal.

Os resultados são claros e demonstram a desproporcionalidade entre o exercício de competências de carater instrumental, centradas em intervenções interdependentes, que geram indicadores processuais e a tomada de decisão autónoma, com base em conhecimento formal de enfermagem, direcionada à prescrição de cuidados centrados na obtenção de ganhos em saúde que, naturalmente se transformam em ganhos de produtividade para as empresas.

Atendendo ao potencial salutogénico da ET e das repercussões que a sua atuação pode ter no mundo laboral, projeta-se que, de futuro, deverá existir um maior investimento na formação, direcionando o foco dos ET para a gestão, prevenção e promoção da saúde, apostando num aumento de competências associadas à investigação e ao planeamento em saúde que, comprovadamente, gere ganhos objetivamente mensuráveis.

\section{REFERÊNCIAS BIBLIOGRÁFICAS}

1- OMS-Europa. O Enfermeiro do Trabalho na Gestão em Saúde Ocupacional. 2001; Copenhaga: 55 páginas

2- Rasteiro, M. Papel do enfermeiro na promoção da saúde ocupacional. Revista Servir. 1995; V. 43, nº 1 (Jan./Fev.): páginas 36-40.

3- Portugal. Decreto-Lei n. ${ }^{\circ}$ 109/2000 de 30 de Junho. Diário da Republica. 2000.

4- Portugal. Lei n. ${ }^{102 / 2009}$ de 10 de Setembro. Diário da República. 2009.

5- Direção-Geral da Saúde. Orientação n. ${ }^{0}$ 9/2014 de 03 de junho. DGS. 2014. 
6- The Federation of Occupational Health Nurses within the European Union. Core Curriculum. FOHNEU. 2014; $3^{\text {a }}$ edição. 27 páginas.

7- Direção-Geral da Saúde. Informação técnica n.10/2015. Formação em Enfermagem do Trabalho. DGS. 2015.

8- Santos M; Almeida A. Enfermagem na equipa de saúde ocupacional. Revista de Enfermagem Referência. 2012; III Série. №.6: pág. 147-155.

9- Rogers B - Enfermagem do Trabalho: Conceitos e prática. 1997; Philadelphia: Lusociência.

10- Antunes R. Enfermagem do trabalho: contributo do enfermeiro para a saúde do trabalho. 2009; Dissertação de mestrado em Saúde Ocupacional, apresentada à Faculdade de Medicina da Universidade de Coimbra

11- Laranjeira S. O papel do Enfermeiro do trabalho na saúde ocupacional. 2016; Dissertação de mestrado em Enfermagem Comunitária apresentada à Universidade Católica Portuguesa, Instituto de Ciências da Saúde, Escola de Enfermagem, Centro Regional do Porto.

12 Oliveira A \& André S. Enfermagem em Saúde Ocupacional. Millenium. 2010; 41 (julho/dezembro): páginas 115-122.

13- Rasteiro, M. Enfermagem do trabalho: uma especialidade??? Acontece Enfermagem. 2001; Nº 1 (Jan.-Jun. 2001): páginas 30-31

\section{TABELAS/ QUADROS/ FIGURAS E/OU APÊNDICESI ANEXOS.}

\section{Gráfico 1- Experiência profissional como enfermeiro e na saúde ocupacional}

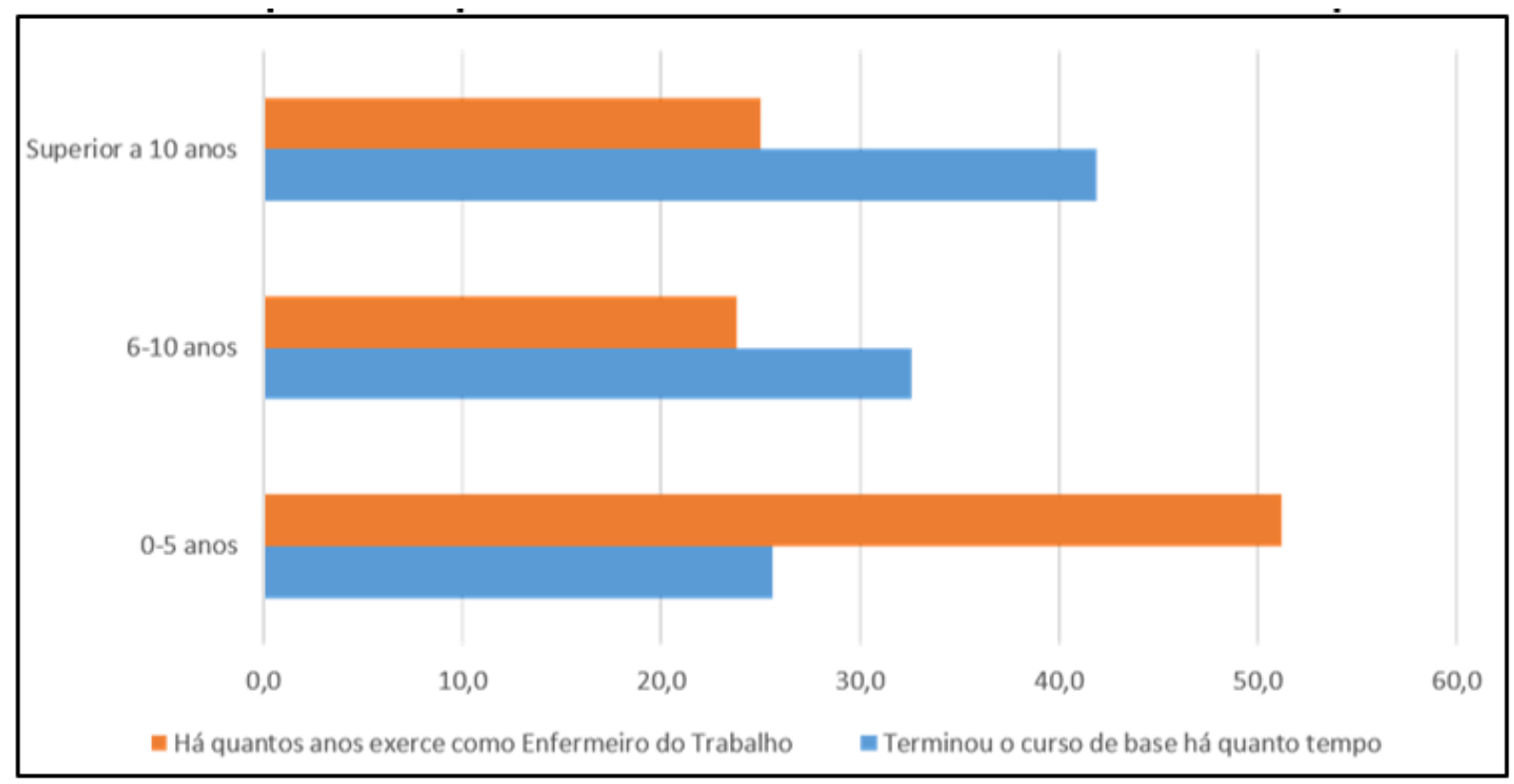

Gráfico 2- Motivação para exercer em função da experiência profissional 
Como complemento financeiro de outra atividade profissional

Porque ainda não consegui trabalhar na minha primeira opção

Foi a minha primeira opção

0

$5 \quad 10$

15

20

25

30

\section{Gráfico 3- Carga horária semanal na Saúde Ocupacional}

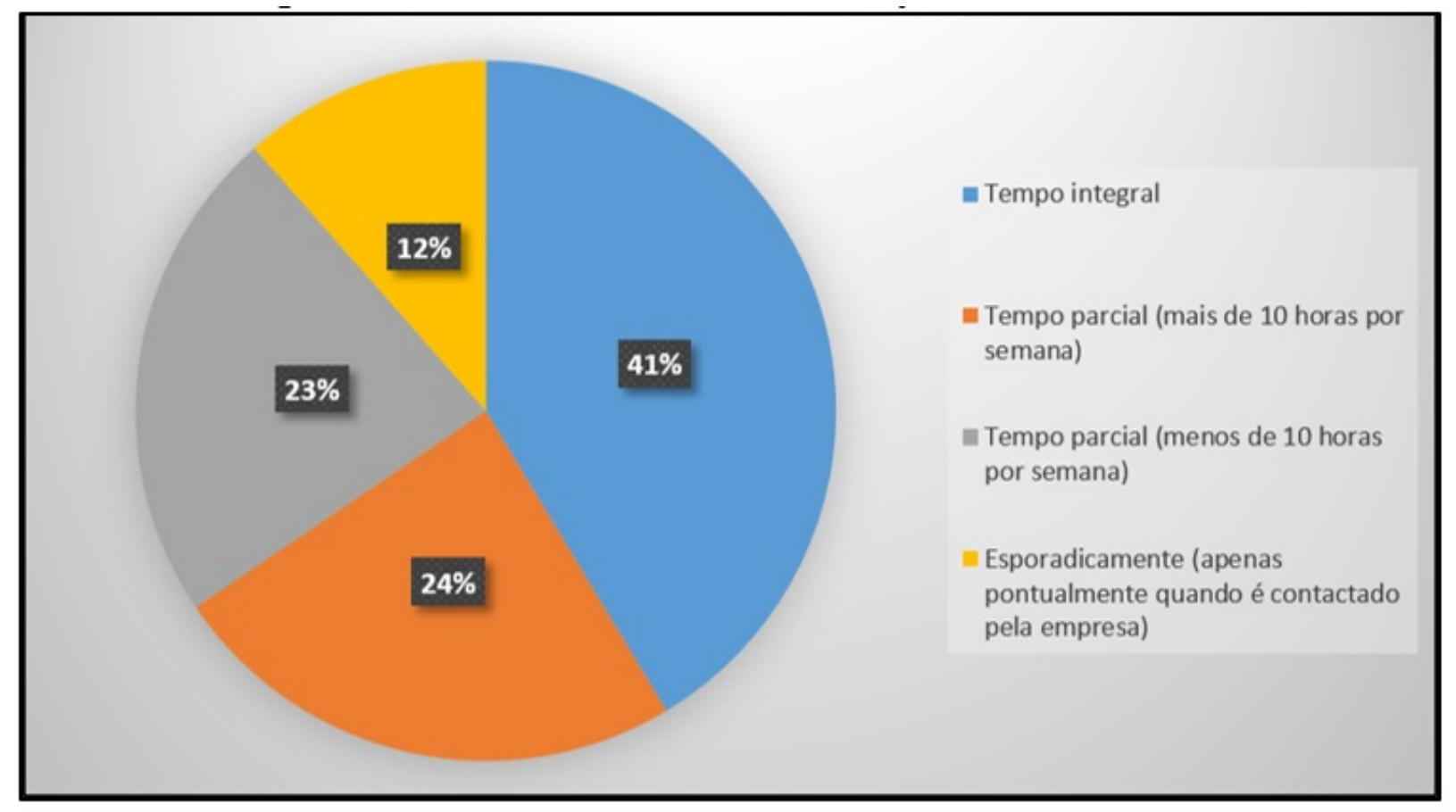

Gráfico 4- Empresa onde exercem as funções como Enfermeiro do Trabalho 


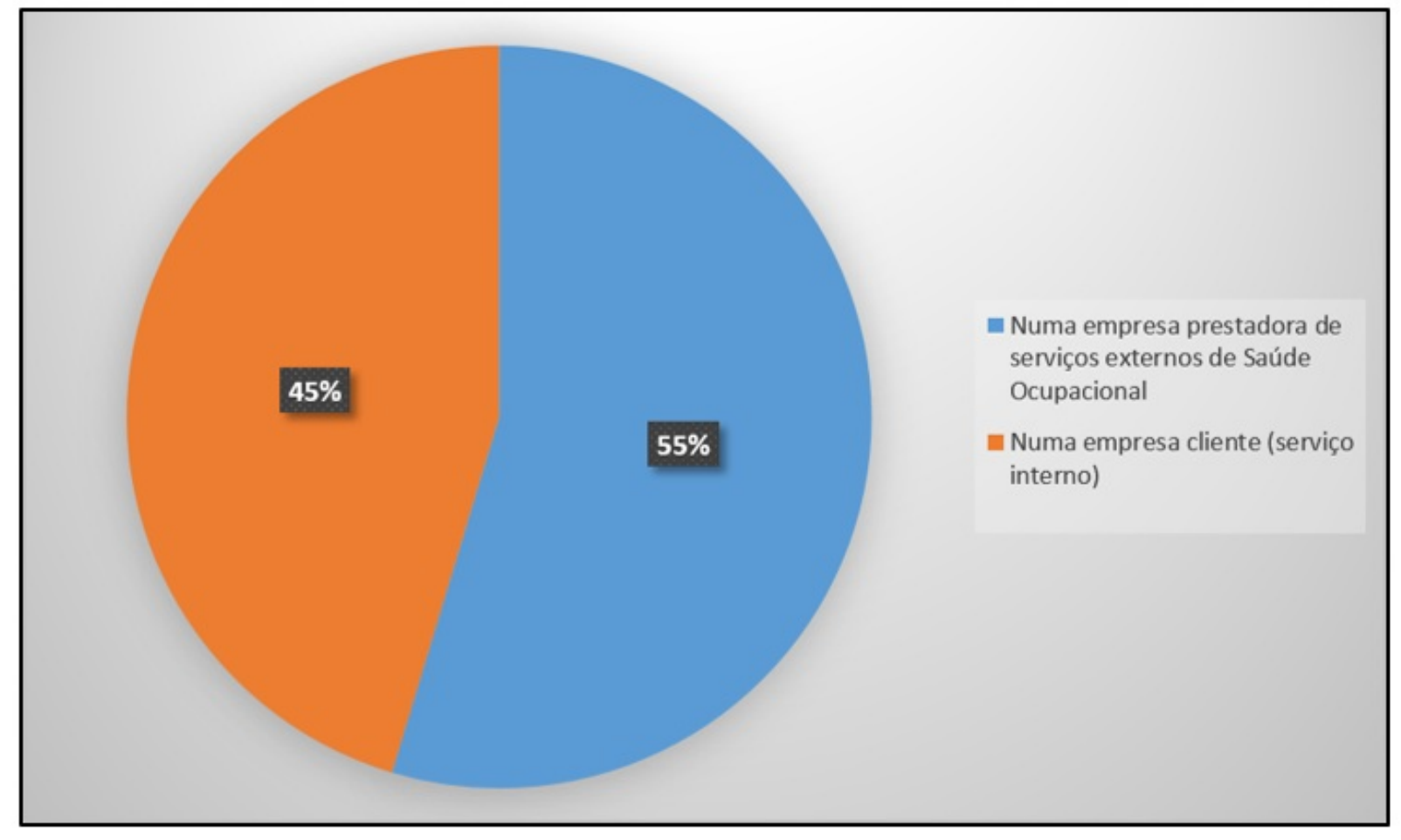

Gráfico 5- O que gostariam de fazer no futuro?

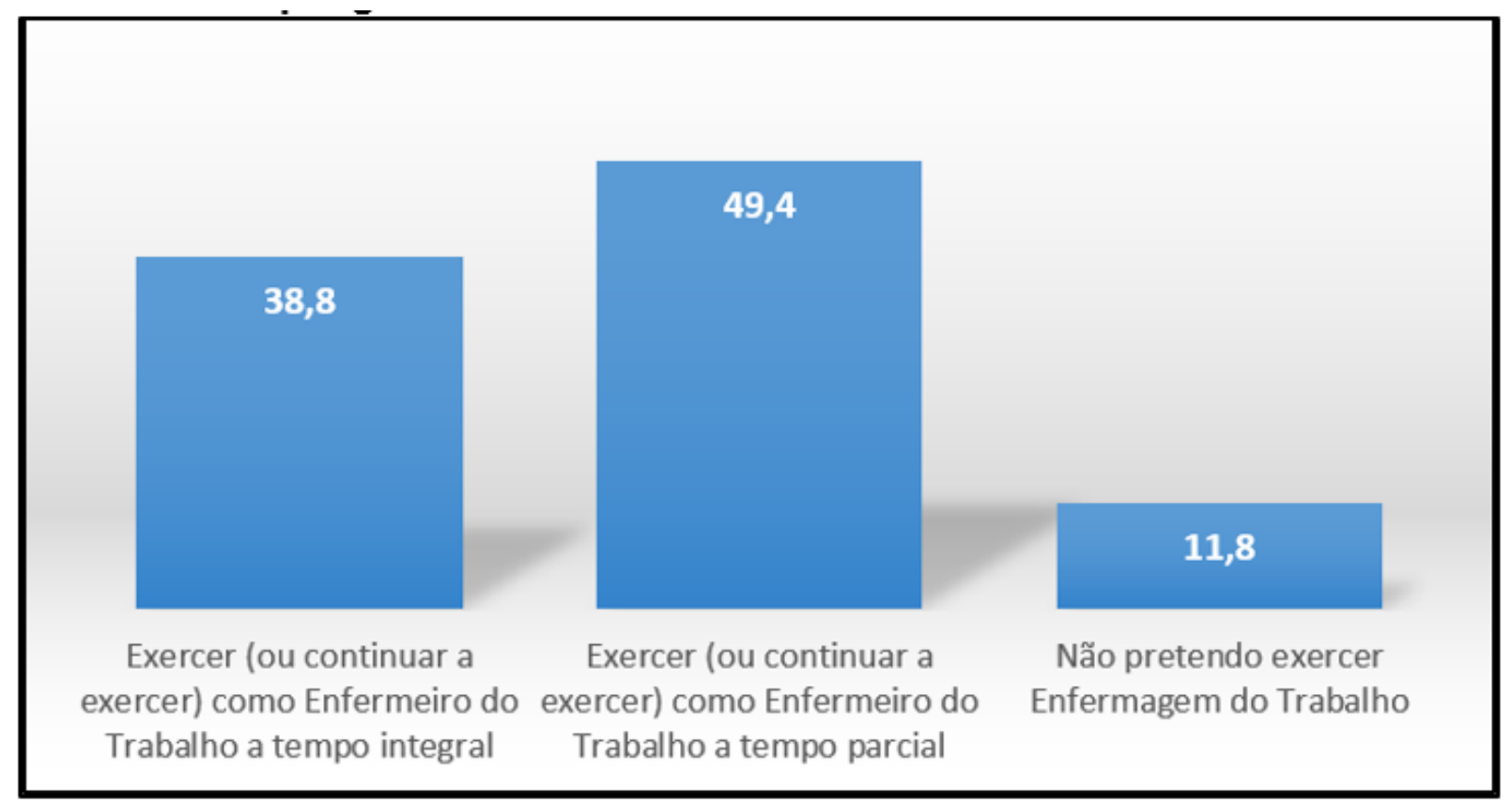

Gráfico 6- Formação académica dos enfermeiros que exercem na SO 
Doutoramento em epidemiologia de saúde pública

Formação superior em higiene e segurança

Nenhuma formação específica na área

Pós Graduação em Enfermagem do Trabalho

Curso de Mestrado em Saúde Pública ou Saúde Ocupacional

Pós-Licenciatura de Especialização em Enfermagem de Saúde Comunitária

Estudo Superior Especializado em Enfermagem na

Comunidade com a vertente de Saúde Ocupacional

Especialização em Enfermagem de Saúde Pública com a vertente de Saúde Ocupacional
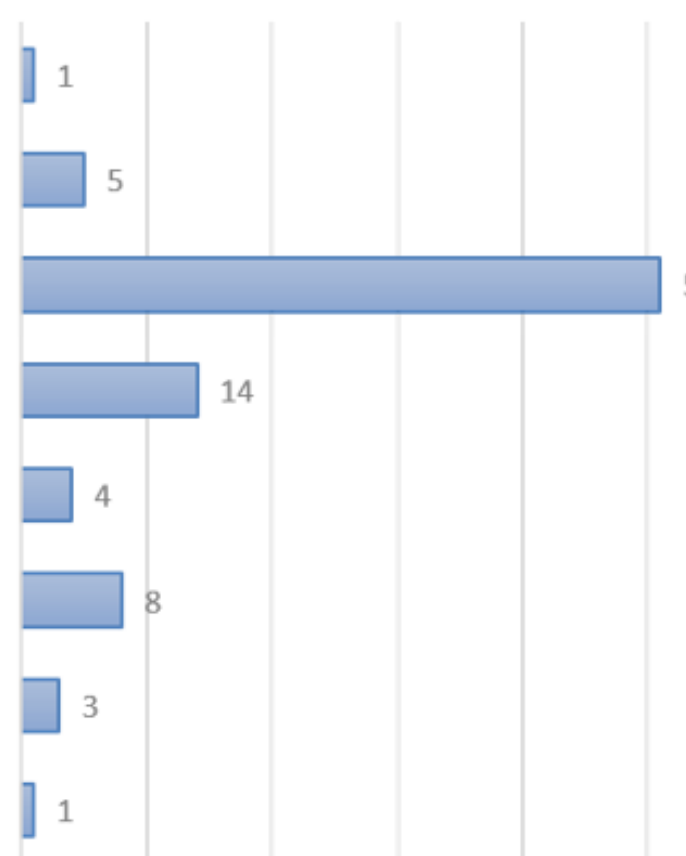

14

0

10

20

30

40

60

Tabela 1- Existência de formação obrigatória em função do tipo de serviço prestado

\section{Serviço externo Serviço interno}

\begin{tabular}{llll}
\hline \multirow{2}{*}{ Formação obrigatória para certificação } & \multicolumn{1}{c}{$\operatorname{Sim}$} & 13 & 17 \\
\cline { 2 - 4 } & Não & 34 & 22 \\
\hline Total & & 47 & 39
\end{tabular}

\section{Gráfico 7- Autorização da DGS para exercer como enfermeiro do trabalho}

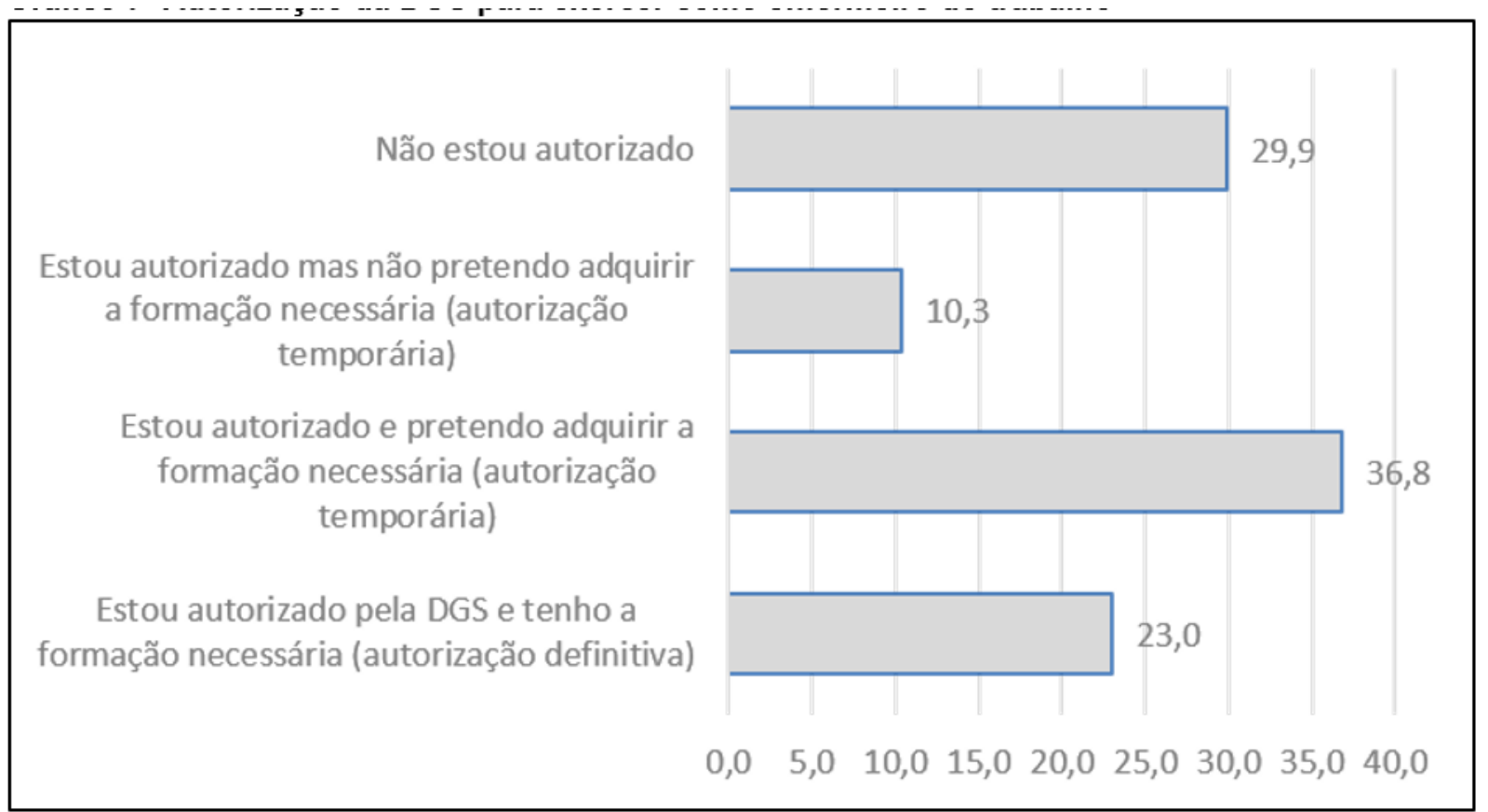

Tabela 2- Registo obrigatório na DGS em função do tipo de serviço prestado 


\begin{tabular}{|c|c|c|c|}
\hline \multirow[t]{3}{*}{ Registo obrigatório na DGS } & Autorização definitiva. & 7 & 13 \\
\hline & $\begin{array}{l}\text { Autorização temporária. } \\
\text { Pretende fazer formação }\end{array}$ & 20 & 12 \\
\hline & $\begin{array}{l}\text { Autorização temporária. } \\
\text { Não pretende fazer formação }\end{array}$ & 8 & 1 \\
\hline Total & & 35 & 26 \\
\hline
\end{tabular}

Tabela 3- Funções exercidas pelos enfermeiros na SO, em contexto português

\begin{tabular}{|c|c|c|c|}
\hline & & Frequência & Percentagem \\
\hline \multirow{2}{*}{$\begin{array}{l}\text { Executar exames auxiliares de diagnóstico, determinados } \\
\text { por contrato comercial }\end{array}$} & $\operatorname{Sim}$ & 44 & 50,6 \\
\hline & Não & 43 & 49,4 \\
\hline \multirow{2}{*}{$\begin{array}{l}\text { Executar exames auxiliares de diagnóstico, determinados } \\
\text { pela Equipa de Saúde Ocupacional }\end{array}$} & $\operatorname{Sim}$ & 61 & 70,1 \\
\hline & Não & 26 & 29,9 \\
\hline \multirow{2}{*}{$\begin{array}{l}\text { Realizar a gestão administrativa do Serviço de Saúde } \\
\text { Ocupacional }\end{array}$} & $\operatorname{Sim}$ & 35 & 40,2 \\
\hline & Não & 52 & 59,8 \\
\hline \multirow{2}{*}{$\begin{array}{l}\text { Realizar a gestão financeira do Serviço de Saúde } \\
\text { Ocupacional }\end{array}$} & Sim & 9 & 10,3 \\
\hline & Não & 78 & 89,7 \\
\hline \multirow[t]{2}{*}{ Dar apoio administrativo ao Serviço de Saúde Ocupacional } & Sim & 33 & 37,9 \\
\hline & Não & 54 & 62,1 \\
\hline \multirow{2}{*}{$\begin{array}{l}\text { Prestar cuidados de socorrismo e atuar em situações de } \\
\text { emergência médica }\end{array}$} & $\operatorname{Sim}$ & 38 & 43,7 \\
\hline & Não & 49 & 56,3 \\
\hline \multirow[t]{2}{*}{ Realizar curativos relacionados com a saúde do trabalhador } & $\operatorname{Sim}$ & 51 & 58,6 \\
\hline & Não & 36 & 41,4 \\
\hline \multirow[t]{2}{*}{ Prestar cuidados de reabilitação } & $\operatorname{Sim}$ & 16 & 18,4 \\
\hline & Não & 71 & 81,6 \\
\hline \multirow{2}{*}{$\begin{array}{l}\text { Identificar necessidades de formação e executar ações de } \\
\text { educação para a saúde }\end{array}$} & $\operatorname{Sim}$ & 46 & 52,9 \\
\hline & Não & 41 & 47,1 \\
\hline \multirow{2}{*}{$\begin{array}{l}\text { Executar ações de educação para a saúde sobre temas } \\
\text { definidos pela equipa de SO }\end{array}$} & $\operatorname{Sim}$ & 47 & 54 \\
\hline & Não & 40 & 46 \\
\hline \multirow{2}{*}{$\begin{array}{l}\text { Executar ações de educação para a saúde sobre temas } \\
\text { definidos pelo empregador ou pelos recursos humanos }\end{array}$} & Sim & 29 & 33,3 \\
\hline & Não & 58 & 66,7 \\
\hline Quantificar parâmetros biomédicos & Sim & 58 & 66,7 \\
\hline
\end{tabular}




\begin{tabular}{|c|c|c|c|}
\hline & \\
\hline & Não & 29 & 33,3 \\
\hline \multirow[t]{2}{*}{ Realizar a gestão da saúde laboral do trabalhador } & $\operatorname{Sim}$ & 33 & 37,9 \\
\hline & Não & 54 & 62,1 \\
\hline \multirow[t]{2}{*}{ Realizar a gestão da saúde pessoal e laboral do trabalhador } & $\operatorname{Sim}$ & 28 & 32,2 \\
\hline & Não & 59 & 67,8 \\
\hline \multirow{2}{*}{$\begin{array}{l}\text { Realizar a gestão da saúde pessoal dos familiares do } \\
\text { trabalhador }\end{array}$} & $\operatorname{Sim}$ & 8 & 9,2 \\
\hline & Não & 79 & 90,8 \\
\hline \multirow{2}{*}{$\begin{array}{l}\text { Visitação domiciliária aos trabalhadores com problemas de } \\
\text { saúde resultantes do trabalho }\end{array}$} & $\operatorname{Sim}$ & 5 & 5,7 \\
\hline & Não & 82 & 94,3 \\
\hline \multirow{2}{*}{$\begin{array}{l}\text { Visitação domiciliária aos trabalhadores com problemas de } \\
\text { saúde não resultantes do trabalho }\end{array}$} & $\operatorname{Sim}$ & 1 & 1,1 \\
\hline & Não & 86 & 98,9 \\
\hline \multirow[t]{2}{*}{ Visitação domiciliária para familiares dos trabalhadores } & $\operatorname{Sim}$ & 1 & 1,1 \\
\hline & Não & 86 & 98,9 \\
\hline \multirow{2}{*}{$\begin{array}{l}\text { Executar estudos epidemiológicos sobre a saúde dos } \\
\text { trabalhadores }\end{array}$} & $\operatorname{Sim}$ & 22 & 25,3 \\
\hline & Não & 65 & 74,7 \\
\hline \multirow[t]{2}{*}{ Dar apoio a projetos desenvolvidos pela empresa } & $\operatorname{Sim}$ & 46 & 52,9 \\
\hline & Não & 41 & 47,1 \\
\hline \multirow[t]{2}{*}{ Desenvolver projetos de melhoria para a empresa } & $\operatorname{Sim}$ & 27 & 31 \\
\hline & Não & 60 & 69 \\
\hline
\end{tabular}

(1)Mestre em Enfermagem Avançada; Especialista em Enfermagem Comunitária; Pós-graduado em Supervisão Clínica e em Sistemas de Informação em Enfermagem; Docente na Escola de Enfermagem (Porto), Instituto da Ciências da Saúde da Universidade Católica Portuguesa; Diretor Adjunto da Revista Portuguesa de Saúde Ocupacional on line; aalmeida@porto.ucp.pt.

(2)Licenciada em Medicina; Especialista em Medicina Geral e Familiar; Mestre em Ciências do Desporto; Especialista em Medicina do Trabalho; Presentemente a exercer nas empresas Medicisforma, Clinae, Servinecra e Serviço Intermédico; Diretora Clínica da empresa Quercia; Diretora da Revista Portuguesa de Saúde Ocupacional on line; Endereços para correspondência: Rua Agostinho Fernando Oliveira Guedes, 42 4420-009 Gondomar; s_monica_santos@hotmail.com.

Almeida A, Santos M. A Enfermagem do Trabalho em Portugal: Experiência, Motivações, Locais de Trabalho, Formação, Funções, Indicadores produzidos e Condições de Trabalho. Revista Portuguesa de Saúde Ocupacional on line. 2017, volume 4, 1-18. 